\title{
Passing as Privileged
}

\author{
DANIEL SILVERMINT \\ Philosophy \& WGSS, University of Connecticut
}

\begin{abstract}
This paper rejects sweeping verdicts about passing as privileged, or attempts by members of oppressed, stigmatized, or discriminated-against groups to improve their lives by being misidentified as members of an advantaged group. Not only do many familiar arguments rely on problematic assumptions about authenticity and resistance, but they strain to accommodate the diverse identities, circumstances, and individual differences that ought to be affecting our verdicts. In this paper I examine the other-regarding and self-regarding considerations that might bear on the decision to pass. The potential other-regarding considerations are that passing involves deception, that passing reinforces stereotypes, and that passing agents opt out of the struggle to end oppression. The potential self-regarding considerations are that passing is a form of resistance, that passing is too costly for victims, and then my own position: that passing is a permissible form of self-regarding complicity. I close by hinting at 'the ethics of looking out for yourself', or the sort of action-guiding framework I think we need to develop in order to fully appreciate and assess strategies like passing.
\end{abstract}

Keywords: action-guidance, authenticity, complicity, identity, oppression, otherregarding obligations, passing, privilege, resistance, self-regarding obligations, victims

\section{Introduction}

We pass all the time. I'm keen to maintain my standing as an oppression theorist, so I pretend I've read Nineteen Eighty-Four when it comes up in conversations. I've failed to mention my penchant for puns and my extensive board game collection on first dates, because it turns out neither of those are particularly appealing for some mysterious reason. And I trained myself out of my Minnesotan accent in graduate school, after noticing that some folks were having a little difficulty taking me seriously during presentations. Some people try to pass as younger, or older, looking for the opportunities and recognition that come with

Contact: Daniel Silvermint <daniel.silvermint@uconn.edu> 
being thought a certain age. Some pass as members of different political parties, hoping to avoid attention or debate when they realize they're in the minority at a gathering. Some pass as fans of popular figures or pastimes, seeing the value in fitting in with friends and coworkers, and some pass as aficionados of more selective pleasures, wanting to be seen as refined. Some pass as more confident than they are, more experienced than they are, more charitable than they are, more well-adjusted than they are, more appropriate than they are, more typical than they are. Sometimes the most advantageous identities or personal histories are not our own.

A tentative definition is that passing occurs whenever an $x$ is perceived as a $y$, resulting in $x$ being treated or evaluated like a $y$. Of course, the examples above are all relatively benign. Little to no harm comes of such everyday passing, either to oneself or to others. The sorts of features being concealed or feigned usually aren't central to who a person is, and the persona being perceived by others is at most a heighted or selective version of oneself, rather than someone else entirely. Benign passing is also highly situational, and not an attempt to stake out a new life, or a new way of living. And most significantly, these kinds of cases aren't about escaping the systematic disadvantages that mark some individuals from birth, or through no fault of their own. Unlike passing as someone who knows his Orwell, passing to conceal my mental illness (among other things) is a morally complicated act. It's an example of passing as privileged, or when a member of an oppressed, stigmatized, or otherwise discriminated-against group is instead perceived to be a member of an advantaged group, and is treated accordingly. It's this kind of passing I wish to explore.

Discussing the racial genealogy of the term 'passing' in American history, Elaine Ginsberg recounts how individuals "crossed or passed through a racial line or boundary-indeed trespassed - to assume a new identity, escaping the subordination and oppression accompanying one identity and accessing the privileges and status of the other" (1996: 3). In his influential book on stigmatized identities, Erving Goffman defines passing as a strategy aimed at "the management of undisclosed discrediting information about the self," or the kind of information that marks someone as a member of a different, less desirable category, reducing them in others' minds from a normal person to a "tainted, discounted one" (1963: 42, 3). And according to Goffman, this kind of passing is common: "Because of the great rewards in being considered normal, almost all persons who are in a position to pass will do so on some occasion by intent" (1963: 74). Dennis Cooley and Kelby Harrison agree, writing that

In times of trouble, those who belong to persecuted classes can often be tempted to pass as a member of the oppressor group. Unfortunately, no 
matter when or where someone lives, it can be a time of trouble because there always seems a societal need to make one or more group the focus of social dislike if not hatred; so there is always an incentive to pass. (2012: 1)

An individual can pass as privileged either passively or actively, depending on whether a member of $x$ is mistaken for a member of $y$ or deliberately presents herself as a member of $y$. As we move through the world, we quickly and continuously sort the people around us into groups, often on the basis of stereotypeinformed heuristics. And it doesn't take any deception or misdirection for such heuristics to misfire; stereotypes aren't known for being particularly accurate. If someone looks, sounds, acts, dresses, spends, associates, or appears in those spaces where we think a member of $y$ should, then we tend to automatically perceive them as a member of $y .{ }^{1}$ Passive passing occurs when an individual is unintentionally misidentified on the strength of these social group markers. Paradigm cases include light-skinned members of other racialized groups passing as white, masculine gay men and feminine lesbians passing as straight, and people with invisible disabilities passing as able-bodied. Ellen Samuels refers to this type of passing as 'passing by default', relating "I certainly do not make any effort to appear 'heterosexual' or 'nondisabled' when I leave the house in the morning; those are simply the identities usually derived from my appearance by onlookers" (2003: 240).

Active passing, meanwhile, is a strategy. It involves exploiting expectations, stereotypes, and other sorting mechanisms to create or avoid the perception of a certain type of person. Claudia Mills gives the example of FDR staging photographs without his wheelchair and wearing black braces that wouldn't show up against his trousers (1999: 29). ${ }^{2}$ Additional examples can include a man changing his name from Juan to John on job applications to improve the callback rate, people in same-sex relationships altering the pronoun of their romantic partners in anecdotes to preserve the presumption of heterosexuality, otherwise lightskinned individuals straightening their "ethnic hair" to cement their appearance as white or gentile, a woman leaving her hijab at home out of fear of growing anti-Muslim sentiments, an ex-con fictionalizing his biography to avoid reflexive distrust, an immigrant family Anglicizing their last name to obscure their naturalized status, an individual with little wealth spending lavishly around new acquaintances to create the impression of high socioeconomic status, a person with mental illness citing a bout of food poisoning to explain away a recent ab2014: 8.

1. This process does more to construct social reality than meaningfully track it. Cf. Hobbs

2. Though this might be more aptly described as a case of 'covering'; see Section 2. 
sence, asexuals feigning sexual interest to escape misconceptions and endless questions about the 'reason' behind their orientation, and countless more. ${ }^{3}$

While many actively pass in order to handle specific situations or interactions, some individuals pass completely. It was only upon his death that jazz musician Billy Tipton's three adopted sons and many of his past romantic partners learned that he had been born biologically female. Anatole Broyard, a mixed-race author who didn't want to be dismissed as just a black writer, eventually raised his children as white and refused to discuss his background with them, leaving his daughter Bliss to seek out her cousins and aunts following his death. And after fleeing pre-war Czechoslovakia, Anna Spieglová and Josef Korbel raised their daughter Madeleine as Catholic, and never discussed their Jewish heritage with her; it was only while being vetted for Secretary of State that Madeleine Albright learned a dozen of her relatives, including three grandparents, were murdered in the Holocaust. Many examples, we'll obviously never hear about.

There is much to criticize about the oppressive background features that make passing a viable strategy for dealing with unjust barriers and burdens in the first place. But that shapes rather than prevents the action-guiding question that arises next, and with which this paper is primarily concerned: if a victim of oppression can successfully pass as a non-victim, ought they?

The moral status of passing as privileged is complex - beyond even the usual sensitivity of debating what victims should and shouldn't do. Since passing allows victims to escape certain oppressive burdens, in many cases it will be permissible, and may even appear to be the right way to go. But critics of the practice often argue that passing as privileged means living a lie. Not only do passing individuals supposedly surrender their authenticity and engage in intentional deception, but they harm their fellow victims by reinforcing stereotypes and oppressive expectations. And passing, it is argued, can also do moral damage to the self, since victims are opting out of a shared struggle, and benefiting from their participation in an oppressive system. The action-guiding question is so charged that even conceptual definitions of passing sometimes weigh in on its permissibility and worth. Mills, for example, understands passing as

the phenomenon of an individual's presenting herself to be in some way other than what she "really" is, either by pretending to be an x rather than a $y$ or by trying in some artificial way to make herself into an $x$ rather than a y, instead of simply accepting or affirming herself as a $y$. (1999: 29)

3. The line between passive and active passing can be vague, such as when a person adopts a particular style solely because it appeals to them, but with misidentification a foreseen side effect. And passive passing can quickly turn active, for example when a verbalized assumption about an individual goes uncorrected; cf. Chekola 2012: 14. 
As I see it, the question isn't whether passing as privileged is good or bad to do. It's likely both, and at the same time. This paper rejects sweeping verdicts about passing's permissibility or impermissibility. Instead, I'll argue that familiar considerations raised for and against passing are not only problematic, but that they can't accommodate the truly staggering diversity of identities, circumstances, and individual differences that properly ought to be affecting our verdicts about passing. In particular, I'll argue that too much of the debate has focused on the morality of 'hiding' your identity, meaning both on the wrong of deception and on the importance of authenticity. Neither of these considerations capture the complexity of the phenomenon, and both have unintended consequences for action-guidance, so my account sets them aside. To a lesser degree, the same is also true of attempts to understand passing as either successful resistance or as a failure to resist oppression. While some of the other-regarding harms of passing are clearly overstated, a better read is that passing doesn't fall neatly into either category. We need a different approach for thinking about the moral status of passing.

If passing as privileged is a strategy, then what is its aim, and how does it fare? I contend that passing shares at least one aim with resistance: it's an attempt to improve one's life or circumstances in the face of oppression. But it's at best a structurally limited strategy, one that relies on the net marginal advantage of protecting or promoting some constituent of one's well-being by endangering or undermining a constituent of their well-being. For example, passing might allow a person to advance her plans and projects, but at the expense of her sense of security as she worries about the risk of discovery. A different person might cultivate valuable connections by slipping past barriers that constrain members of his group, but fray his relationships with family and community as a result. A third person might gain access to valuable external goods, but struggle with self-respect because of how she came by them. The specific trade-offs vary across individuals and circumstances, but there's always a well-being trade-off.

Why? Part of what characterizes oppressive norms, structures, and institutions is the difficulty a victim has living the life she wants simply because of who she is - a difficulty the socially privileged don't share. And victims of oppression can't access (or approximate) that kind of privilege without personal risk or cost. So passing victims decide what they can live without and what they can't live without, and pass when doing so offers them their preferred tradeoff. Resistance and passing do share an aim, but whereas genuinely resisting agents attempt to improve their well-being by ending the system that constrains it, passing victims leave that system in place, and exploit the visible markers that drive distributions and treatment so the constraints fail to activate in their case. This makes passing victims complicit in their own oppression, as their strategy for improving their well-being depends on the continued existence of a system 
that's ultimately still harmful to them. That doesn't make passing impermissible as a rule, but it does make passing a limited strategy for looking out for yourself.

Is this consideration exhaustive, or decisive? No. But with the tools currently at our disposal, I think it comes the closest to fairly capturing the strategy of passing as privileged.

In what follows, I'll distinguish 'passing as privileged' from nearby but distinct phenomena that merit their own analyses, and canvass some of the intricacies of identity and authenticity that rightfully complicate any treatment of passing (Section 2). I'll then examine the other-regarding and self-regarding considerations that might bear on a victim's decision to pass. The potential other-regarding considerations are that passing involves deception, that passing reinforces stereotypes, and that passing agents opt out of the struggle to end oppression (Sections 3.1-3.3). The potential self-regarding considerations are that passing is a form of resistance, that passing is too costly for victims, and then my own argument: that passing is an acceptable form of self-regarding complicity (Sections 4.1-4.3). I'll close by hinting at 'the ethics of looking out for yourself', or the sort of action-guiding framework I think we need to develop in order to fully appreciate and assess strategies like passing.

\section{Complexities of Passing}

Formally, passing as privileged occurs when a member of an oppressed, stigmatized, or otherwise discriminated-against group $x$ is passively or actively perceived to be a member of a privileged group $y$, thereby escaping the unjust barriers and burdens that come with being identified as an $x$ and/or accessing the advantages that come with being (mis)identified as a $y$.

Although this definition captures the full range of cases I wish to investigate, it also obscures the incredible diversity of identities, circumstances, and individual differences that complicate accounts of passing. Two cases can be structurally similar without one much informing our understanding of the other. For example, not everyone who chooses to pass as straight does so for the same reason. Raja Halwani explains that the closet

can have two functions. In the case of an individual trying to determine her life in a homophobic society, the closet can function as a protective shield, especially when important goods are threatened. But in cases in which the only reason for hiding is shame, the closet functions perniciously: it assaults the dignity of the individual, renders her identity invisible, compromises her integrity, and has the net effect of forcing her to lead a morally compromised life. (2002: 146) 
Assuming Halwani is correct, should an account of passing as privileged treat these two individuals the same way, or are their actions morally distinct? Are one or both of them doing the same thing as an investment banker who's been passing as white to advance her career, and is she in turn doing the same thing as someone who declines to mention a disability or a chronic illness on a dating website? Or a non-violent felon who doesn't mention his criminal record on the same site? So much depends on motivation, incentives, background details, and other contingencies, and we need to track these differences.

There are two basic kinds of complications. First, a host of behaviors that often get described as passing are actually distinct phenomena, or at least distinct from what's going on in cases of passing as privileged. Consider people of color being accused of trying to pass when they code-switch. Modifying one's speech, vocabulary, or other forms of expression in order to successfully navigate different communities only looks like passing if you assume there's a way that person 'really' is, and that one (or both) of their behavioral patterns is inconsistent with their 'real' identity. We also need to set aside cases that involve passing, in the sense of moving between burdened and privileged groups, but where 'passing as privileged' fails to offer the best explanation. Former NAACP chapter president Rachel Dolezal was likely passing when she lived as a black woman, but she wasn't passing as a member of a privileged group; her actions raise questions of cultural appropriation and available outs that typically aren't present when black women instead pass as white. Or consider Self-Made Man author Norah Vincent spending a year and a half passing as a man in order to investigate gender differences, or an activist who passes as straight in order to take down a hate group from within. Such individuals are passing into privileged groups, and there may well be problematic aspects to their actions, ${ }^{4}$ but they won't be the same aspects that make more familiar examples of passing as privileged problematic. Passing as a way of directly combating oppression is notably different from passing in order to better endure oppression, and infiltrating a social group to learn about it is different than doing so because you want to lead the kind of life its members get to lead.

The second kind of complication we need to track stems from intersectionality, or the idea the differences in identity and personal circumstances result in unique manifestations of oppression and privilege that get overlooked when we make generalizations about entire groups. Real-life cases of passing are always more involved than simple binaries like "a black person passing as white". A woman who passes as white might gain privilege along one dimension, but remain disadvantaged because she's still being treated as a woman - to say nothing of how sexuality, class, ability, religion, geography, and other factors can

4. My thanks to a referee for this point.

Ergo • vol. 5, no. 1 • 2018 
affect treatment in a far from monolithic group like 'white'. Intersectional differences help shape the specific balance of benefits and burdens, which affects the morality of pursuing or avoiding them in turn. Not only that, but the lived realities of some individuals at the margins have the potential to upend standard arguments about passing, as we'll see when we consider the double bind that authenticity presents for groups like queer femmes, who pass as straight precisely by being themselves.

First, nearby phenomena. ${ }^{5}$ There's a difference between individuals who pass as members of different groups and those whose identities defy standard categories, like those with multiracial heritage, those born intersex, non-conforming or gender-fluid persons, and anyone else whose self-expression is broader than what reductive stereotypes allow. A gender-fluid person who was born biologically female isn't attempting to pass as a man if they adopt a stereotypically masculine presentation - they're simply being gender-fluid. Even so, one kind of case can quickly turn into the other. If someone mistakes the gender-fluid person for a man (or, for that matter, a woman), they will begin to passively pass until the misconception is corrected, revealing one of the many pressures non-binary individuals face. Their defiance of identity categories is not in of itself a form of passing, but it does reveal one way in which the construction of identity categories complicates the ethics of passing.

On the other hand, we sometimes use 'passing' to describe active attempts at self-definition and self-expression, or cases where widespread misinformation and misunderstanding means that it can take some work to make external perceptions of you match your actual identity. A particular variety of trans passing offers a paradigm example. Now, to be clear, a trans man looking and acting like a man is not an example of a woman passing as a man. ${ }^{6} \mathrm{~A}$ trans man is a man. However, he does engage in a type of passing if he presents himself as cisgender rather than as trans, or as someone who was originally assigned that gender from birth. Yet such passing is often more about trying to secure one's status as a man in a hostile society than it is about trying to conceal one's status as trans. As C. Riley Snorton relates,

the psychic act of passing is an essential part of what it means to know myself. ... For transsexuals like me, passing is a hopeful stance that sustains an ability to articulate a transsexual identity in the face of discourses of clinicization and social misreading. Passing, like hope, keeps me sane, or at least helps me cope in an environment that does not produce the identity I psychically inhabit. (2009: 79, 89)

5. Considerations of space prevent me from offering a complete taxonomy of passing and pseudo-passing here. The cases that follow are representative rather than exhaustive.

6. Unfortunately, the term 'passing' is sometimes used to police gender identity in precisely this way. See Section 3. 
So a trans man passing as cis in order to avoid violence or hardships like high eviction rates may be 'passing as privileged' in the explanatory sense, but a trans man passing as cis in order to create and assert his identity in the face of epistemic opposition is better explained by a different analysis altogether. In practice, these distinctions will rarely be neat enough for easy verdicts, especially given the possibility of agents passing for more than one reason.

There are many other examples of behaviors mistaken for passing, and many other genuine instances of passing that aren't 'passing as privileged' in the explanatory sense. One that causes a rather pervasive complication for analyses of passing is 'covering'. In his brilliant book on the subject, Kenji Yoshino writes that to cover "is to tone down a disfavored identity to fit into the mainstream" (2007: ix). Explaining the phenomenon in the context of his own struggle to arrive at a gay identity, Yoshino contends that covering is the third and final phase of the assimilationist demand (2007: 17f.). The first phase is conversion, named in reference to conversion therapies: the pressure or desire to become straight. Once a society or an individual moves beyond that demand, a gay person can experience the pressure or desire to pass. Overt attempts to actually change an individual's identity subside, but full participation in an institution continues to depend on at least being perceived as straight. An example of this second phase is Don't Ask, Don't Tell, which from 1993 to 2011 made military service in the U.S. contingent on an undisturbed presumption of heterosexuality.

Despite assumptions to the contrary, the assimilationist demand doesn't necessarily end just because the pressure to pass has faded. Instead, passing can give way to covering: when it becomes tolerable for an individual to reveal their identity, but participation and acceptance are conditional on not 'flaunting' that identity.7 As Yoshino relates,

long after I had generally come out of the closet, I still muted my orientation by not writing on gay topics or engaging in public displays of same-

7. Orange Is the New Black offers a compelling example of this post-passing covering pressure. In a flashback scene, the self-identified butch character Big Boo finally decides to visit her dying mother in the hospital, from whom she's long estranged. Boo shows up in her everyday attire: a pompadour haircut, thick chains and piercings, cut-off sweats, and a pair of Chucks. Boo's father intercepts her in the hallway, and while he's generally accepting of her sexuality, he notes her mother's frail state and asks "Would it kill you to put on some other clothes before you see her?" Boo's exhaustion mounts as he continues: "I understand that whatever this is, is important to you. But it's a costume, that's all. The rest of us, we get up, put on a suit and a tie, we go to work. You think that's how I wanted to dress five days a week? No, of course not. But no one gets the privilege of being themselves all the time. No one. Now, if you want to go in there and upset her, I'm not going to stop you. But you need to decide whether your costume is worth what it's costing you." Explaining that she's had to fight for her appearance all her life, and that she refuses to be invisible, Boo leaves the hospital without seeing her mother (3xo4: "Finger in the Dyke"). 
sex affection. This was not the same as passing, because my colleagues knew I was gay. (2007: 18)

Yoshino takes the term 'covering' from Goffman's work on stigma, where he distinguished passing from covering "by noting that passing pertains to the visibility of a particular trait, while covering pertains to its obtrusiveness" (2007: 18; cf. Goffman 1963).

Discussing categories protected by federal civil rights laws such as race, sex, religion, disability, and the like, Yoshino observes that "with varying degrees of conviction, Americans have come to a consensus that people should not be penalized for being different along these dimensions. That consensus, however, does not protect individuals against demands that they mute those differences" (2007: x). He elaborates:

All civil rights groups feel the bite of the covering demand. AfricanAmericans are told to "dress white" and to abandon "street talk"; AsianAmericans are told to avoid seeming "fresh off the boat"; women are told to "play like men" at work and to make their child-care responsibilities invisible; Jews are told not to be "too Jewish"; Muslims, especially after 9/11, are told to drop their veils and their Arabic; the disabled are told to hide the paraphernalia they use to manage their disabilities. . . . We are at a transitional moment in how Americans discriminate. In the old generation, discrimination targeted entire groups - no racial minorities, no women, no gays, no religious minorities, no people with disabilities allowed. In the new generation, discrimination directs itself not against the entire group, but against the subset of the group that fails to assimilate to mainstream norms. This new form of discrimination targets minority cultures rather than minority persons. Outsiders are included, but only if we behave like insiders - that is, only if we cover. (2007: 21f.)

Many examples of passing can more accurately be described as covering. Because his condition was generally known, FDR's staged photographs didn't create a perception of able-bodiedness, but they did serve to conceal the extent of his disability and allay concerns about his ability to govern. Likewise, straightening or unbraiding one's hair often isn't an attempt to pass as white, but is instead about mitigating the racist impression that persons of color are unprofessional or even

8. Later, he illustrates the three phases this way:

If conversion divides ex-gays from gays, and passing divides closeted gays from out gays, covering divides normals from queers. ... By normals, I mean openly gay individuals who embrace a politics of assimilation. ... By queers, I mean gays who emphasize their difference from the mainstream. 2007: 77 
dangerous. Quips about my Minnesotan accent drove me to cover its extremes, but not to pass as someone from a worse state.

Why does covering present a lingering complication for analyses of passing, once the distinction has been drawn? Because in practice, whether an individual is passing or covering depends in part on the person that's observing her. Yoshino argues that "passing and covering are often indistinguishable. The same behavior - such as not holding hands with someone of the same sex - can constitute passing or covering, depending on the literacy of the audience" (2007: 92). In other words, to an employer who knows you're a lesbian, refraining from holding your girlfriend's hand at an office party is an act of covering. But to an amorous coworker who stubbornly persists in the assumption that you're straight after repeated hints to the contrary, refraining from holding hands is instead an act of passing as straight. And if bringing your girlfriend to an office party can be an example of passing, then we have a problem. So what should we say about the permissibility of passing in this case? Or in the innumerable other situations where what you're doing - and indeed, whether you're doing anything at allcan change from moment to moment and person to person?

The uptake problem generalizes. Discussing the case of queer femmes, or lesbians and bi women whose appearance and mannerisms are traditionally feminine, Samantha Brennan insists that visibility is not something than an individual can accomplish on their own:

one can be seen and identified as a queer femme in Toronto or San Francisco while in smaller towns and cities such an option does not exist. To dress in a feminine fashion is, in many spaces and places in the world to invite being misread as straight. The same difficulty applies if one wishes to be identified as bisexual. (2012b: 176; cf. 2011)

Failures of recognition can turn even reasonably direct attempts to communicate your identity through your appearance into passing. ${ }^{9}$ Alice MacLachlan and Susanne Sreedhar argue that the power of revealing who one 'really' is

depends, at least in part, on audience uptake-and thus acts of coming out are vulnerable to misunderstandings, ignorance, and confusion of others. Moreover, some queer identities face greater risks of misunderstanding than others ... on a daily basis, queer femmes are far more

9. As Brennan observes,

Once you start thinking about this phenomenon, you can see the many places it occurs. It is harder for poor women to wear ripped clothing as a fashion statement when people might see you and think you could not afford anything new. Trucker caps are not ironic if you are wearing them in an environment where people wear trucker caps seriously. 2012a: 196 
likely to be mistaken for conventional, "straight" women than other lesbians and bisexual women. (2012: 51, 53)

Queer femmes provide a striking example of how identities at the margins can upend familiar criticisms of passing as privileged, like the claim that passing undermines authenticity. Since dressing and acting in stereotypically feminine ways counts as authentic self-expression for queer femmes, and since those are precisely the behaviors that tend to confirm the default presumption of heterosexuality when encountering others, "what it means for a femme to 'pass' or 'cover' is not always distinguishable-conceptually, or in practice-from living authentically and resisting heteronormative identification: i.e., the conditions of being 'out'" (MacLachlan \& Sreedhar 2012: 51f.). MacLachlan and Sreedhar rightly wonder where the ethics of passing and coming out leaves queer femmes (2012: 55). While many queer persons can pass,

queer femmes are distinctive in that it is their queer identity itselftheir own, authentic expression of their individual sexual identity - that provides access to privilege. Indeed, fully reneging on that privilege by working to demonstrate, even prove, their queerness to others - if that requires they cover or minimize their femmeness, to do so-may end up feeling less authentic, and more akin to passing, than the alternative. (2012: 59)

Intersectionality provides a powerful reminder not to overgeneralize by treating victims or oppressive burdens as conceptually interchangeable. Samuels contends that aspects of passing and coming out as disabled are more like cases of race than cases of sexuality, since

the contingent (non)visibility of queer identity has produced a variety of nonverbal and/or spoken means to signal that identity, while the assumed visibility of race and disability has produced an absence of nonverbal signs and a distrust of spoken claims to those identities. (2003: 241)

For this and other reasons, femme lesbians appear to be primarily marginalized in lesbian subculture, while those with invisible disabilities instead face greater discrimination in the dominant culture (2003: 246). This difference affects how we understand the act of passing for members of the respective groups. Yoshino offers another example when discussing how women are unique in facing both covering and reverse-covering demands at the same time, like the pressure not to talk about their children too much at work (thus covering their gender) while still looking conventionally attractive and behaving in a lady-like fashion (thus 
emphasizing their gender) (2007: 147). Why the difference? Yoshino contends that unlike "gays and racial minorities, women have been cherished by their oppressors. Men have long valued the 'feminine' traits women are supposed to hold, such as warmth, empathy, and nurture" (2007: 147). Once again, background structures matter.

Even if a single criticism or verdict about passing were able to account for all of these differences, a final complication remains: many cases of passing don't involve two oppositional identities. A black woman who passes as white is passing as privileged, but what should we say about a black woman who passively passes as, say, Puerto Rican? Assuming she is in some ways advantaged, do standard arguments about passing as privileged apply? Or what about Vijay Chokal-Ingam, an Indian American man who actively passed as black in order to gain acceptance to medical school on diversity grounds? Passing allowed him to realize his plans, but are African Americans really privileged in the context of medical school applications? Are Indian Americans discriminated against by admissions committees? Few individuals are either wholly oppressed or wholly privileged, and given the number of intersectional differences and the lack of straightforward hierarchies, the balance of benefits and burdens will usually be too specific for simple verdicts to accommodate.

No matter what kind of formal definition we give, passing as privileged is likely to remain a vague phenomenon that's difficult to distinguish from other forms of passing, and even some behaviors that aren't really passing at all. And the intricacies of identities, circumstances, and individual differences will complicate attempts at action-guidance, even when we're reasonably sure that we're looking at a case of passing as privileged. So as we proceed to examine the various other-regarding and self-regarding considerations that are often invoked in discussions of passing, we should be wary of one-size-fits-all characterizations of those who pass, as well as overgeneralizing verdicts about the permissibility or impermissibility of their actions.

\section{Other-Regarding Considerations}

Now that we have a sense of how diffuse and wide-ranging passing as privileged can be, how do familiar arguments about its permissibility fare? Discussions of the moral status of passing tend to focus on its other-regarding consequences, and most of those discussions generally condemn the practice, while allowing for some exceptions in dire situations. We can divide the objections into three main arguments: that passing involves deception, that passing reinforces oppressive stereotypes, and that passing means opting out of the shared struggle to 
end oppression. Each of these objections track morally relevant considerations, but I'll argue that none of them capture the full story of passing.

\section{1.}

Probably the most common objection is the idea that passing is wrong because it involves deception. Deception seems to be a core feature of active passing, where members of $x$ work to create the perception that they're members of $y$, but even passive passing can involve a degree of deception, since the individual is most likely aware of the mistaken assumptions others keep having and how those assumptions advantage her over time. Mark Chekola, who sees active passing as pretending to be someone you're not, suggests evaluating cases in line with other examples of deception:

Passing involves a secret and, typically, deception, lying. . . . As lies, all of these cases will be prima facie morally wrong. It may be that in certain situations they will turn out to be justified morally, overall, in terms of being the most satisfactory alternative in a difficult situation. However, they are not without moral consequence. (2012: 13, 15f.)

Even in cases where individuals pass in order to avoid specific harms like being reduced to stereotypes or having a small part of their lives come to usurp their identity, Chekola maintains that "the real issue is . . . whether, under the circumstances, the failure to disclose is justified" (2012: 19).

Since most cases of passing as privileged are ongoing, the purported wrong goes beyond misinformation or a failure to disclose. If others are deceived about an individual's basic identity and background, their relationships with that individual will be impaired. Sandy Stone holds that it's wrong for trans persons to blend in and disappear by passing as cisgender, believing instead that trans men and women should publicly present themselves as trans. Although not her main argument, one concern she raises is that "Transsexuals who pass seem able to ignore the fact that . . . they have foreclosed the possibility of authentic relationships. Under the principle of passing, ... relationships begin as lies" (Stone 1992: 167). And there's no reason this problem would be confined to passing as cis - in fact, Stone takes herself to be rearticulating "one of the arguments for solidarity that has been developed by gays, lesbians, and people of color" (1992: 167). On this interpretation, passing victims are living a lie, one that affects how and with whom they're able to build that life. And in extreme cases-such as those where the relationship wouldn't have taken place had the other person known the truth - the deception could even compromise another's autonomy.

I have four responses to the 'but deception is wrong' objection. First, it's 
important to remember that in oppressive contexts, many of the relationships were already impaired to begin with. One reason victims pass is because they're blocked from participating in valuable dynamics and opportunities simply because of who they are, and if you have to conceal a permissible aspect of your identity in order to gain access to a social space, then the space in question isn't inclusive. It's not as if passing victims are choosing to form relationships on false pretenses instead of exploring equally rewarding 'authentic' relationships with the same individuals. Nor is it clear that the most worthwhile relationships are the ones being impaired. While some of those who pass sever all former ties and take their secrets to the grave, many employ a parallel strategy, passing in everyday settings or amongst less tolerant acquaintances, while trusting themselves to sympathetic friends and intimates. In a number of cases passing is even an open and accepted secret amongst the members of one's own community, leaving those relationships unimpaired. ${ }^{10}$ It's also worth noting that the degree of intimacy between individuals places limits on how much information counts as 'too much information', too soon. Discussing the example of ex-convicts, Goffman argues that a person can

only disclose his stigma widely by improperly presuming on mere acquaintances, orally disclosing to them personal facts about himself which are more personal than the relationship really warrants. A conflict between candor and seemliness will often be resolved in favor of the latter. (1963: 74f.)

Invisible disabilities and other matters of health are likely subject to similar norms.

Second, it's not obvious that disclosing the details of our identities and personal histories is something that we actually owe to most of the people with whom we interact. A customer who's bi simply isn't harming the grocery store cashier who's under the impression the customer is straight-even if the customer encourages that impression. As Mills puts it, "we may ask who has a right to an accurate presentation of my age, appearance, race, gender, religion, or parenting practices? Who has a justified claim to this information?" (1999: 31). Even in intimate relationships, the ethics of what partners have a right to know, and when they have a right to know it, can be murky at best. Prospective lovers should probably reveal risk factors such as STIs prior to sex, but the details of one's background normally don't constitute risk factors. If someone assumes that all four of their prospective lover's grandparents were white, must he correct them on the first date, or can he wait until the second? What about a month

10. Cf. Harrison 2013: 5 . 
in? Keeping such information from a long-term partner might erode the level of trust and intimacy in the relationship, but if so, the wrong of deception is only going to affect a fairly narrow range of individuals. Few have enough of a claim on disclosure to be wronged by its absence.

The third response to the 'deception' objection is that passing is sometimes closer to self-defense than deceit. Many of those who pass along sexual or gendered lines are at risk of extreme discrimination and violence if they present themselves as they are. According to the National Coalition of Anti-Violence Programs, ${ }^{11} 72 \%$ of the victims of anti-LGBTQ murder were trans women, and acts of brutalizing 'overkill' ${ }^{12}$ such as genital mutilation and other tortures were a frequent occurrence. Trans persons are also 1.8 times more likely to be the victims of sexual assault than cisgender individuals, and were seven times more likely to experience physical violence when interacting with the policeincluding cases that began as attempts to secure police assistance. And this is to say nothing of the high rates of homelessness and unemployment in trans populations, or of their harassment at the hands of teachers, health care professionals, and other service providers. Mills observes that "a non-Kantian may well hold that some lies are, on balance, justified, if the consequences of truth-telling are dire enough," and we don't need to turn to historical examples like admitting one's Jewish ancestry in Nazi Germany in order to find examples (1999: 36). While Mills and even Chekola hold that certain risks justify engaging in deception, 'an act of deception' strikes me as the wrong description to begin with. Resisting an asymmetrical demand to reveal yourself to your oppressors is better understood as an act of self-preservation, not deception.

Considering the pressures facing members of the trans community directly leads to the fourth response: the 'deception' objection simply isn't sensitive enough to accommodate the diversity of identities, circumstances, and individual differences involved in passing as privileged. It's not just that passing as cis is more complicated than simple deception-as Talia Mae Bettcher argues, trans persons are sometimes seen as engaged in deceit whether or not they pass. There are familiar cases of trans panic, ${ }^{13}$ where defendants argue that they're not guilty for assaulting or murdering trans women because engaging in flirtation or sexual activity with someone they thought was a cis woman so provoked them. But the ongoing controversy over bathroom usage, for example, involves an accusation of deceit against individuals who are actually out as trans: namely, that these women are 'really' predatory men infiltrating women's spaces by pretending to be women (Bettcher 2007: 51). The failure to recognize trans men and

11. http://www.avp.org/storage/documents/ncavp_transhvfactsheet.pdf

12. This is elaborated upon in NCAVP's 2009 report.

13. In September 2014, California became the first U.S. state to forbid the use of this legal defense. 
women as authentic men and women traps trans individuals in a double bind, where the only choice is between "invisible deception and visible pretense": either "disclose 'who one is' and come out as a pretender or masquerader, or refuse to disclose (be a deceiver) and run the risk of forced disclosure, the effect of which is exposure as a liar" (Bettcher 2007: 55, 50).

The deception/authenticity framework utterly fails to accommodate this lived reality, as it models passing (along with being closeted) as the practical and conceptual opposite of living authentically. But if Bettcher is right that trans folk are sometimes treated as deceivers if they pass and as pretenders if they don't, then outing oneself won't always secure the goods of authenticity, or avert the impaired relationships predicted by the 'deception' objection. Even emphatic attempts to be out won't necessarily prevent others from being deceived about your identity. Bettcher notes that we don't always have authority over how our bodies are understood or what our words mean, and that coming out as "a trans woman" is sometimes seen as a declaration that one is really "a man disguised as a woman" (2007: 54). This lack of control recalls the discussion of queer femmes and bi women from Section 2, and the insight that visibility depends on recognition (Brennan 2012b: 174), and is for that reason easier for some to achieve than for others (Brennan 2012a: 196). As Brennan elaborates,

Bisexual women and queer femmes of all persuasions know what it is like to be misheard, misread, mis-seen and invisibility takes its toll, especially in the face of political cries for greater visibility. You can feel that not only are you not recognized by your community but also that you are failing to live up to your political obligations. (2012a: 196)

To insist that victims refrain from passing on deception grounds is to misunderstand the challenge of visibility.

\section{2.}

The second other-regarding objection is that passing is wrong because it reinforces harmful stereotypes, and thus deepens or legitimizes the oppression of the passing victim's own group. We can begin to see why once we consider the unreliable nature of 'visibility'.

For any group $x$, its members run the gamut in terms of appearance, behavior, social location, and the like. However, stereotypes and other expectations lead us to associate only some of those traits with particular identities, creating a gap between the actual membership of $x$ and the filtered subset immediately recognizable as an $x$. For example, when we assume that traditionally masculine men are straight while effeminate men are gay, traditionally masculine gay men 
will be seen as straight, thus disappearing from our perception. That leaves other gay men (as well as other men who fail to match the masculine ideal, including some straight men) as the only ones being seen as gay. And so the stereotype linking masculinity and sexuality is reinforced, constantly. This filtering explains how masculine gay men can pass without meaning to, and creates the opportunity for other gay men to actively pass by adopting masculine mannerisms, interests, and other constructed markers.

The visibility gap does more than explain how individuals pass. It also begins to reveal the stakes of passing. As MacLachlan and Sreedhar observe in the context of coming out, individuals who lack stereotypical markers of queerness are the ones who face the starkest dilemma:

only those who can pass are able to choose between a life of (fraudulent) heterosexist privilege burdened by the moral and psychological costs of secrecy and compartmentalization, on the one hand, and the risks of reneging privilege by committing to living openly and in solidarity, on the other. Those who can access more privilege in the first place have more to lose by renouncing it. (2012: 55)

So, those who least match the stereotypical markers of their subordinated group have the strongest incentive to pass. But the same dynamic also explains why passing can reinforce stereotypes: the greater your opportunity to pass as a $y$, the more likely it is that your particular identity expression is missing from public perceptions of $x$. This means those individuals with the greatest incentive to pass are the very individuals who would most disrupt stereotypes if they stopped passing and instead made themselves visible members of $x$. To return to our previous example, if passing gay men allowed themselves to be visible examples of what some gay men are like, the public perception of gay men would expand, and the stereotype would weaken. But by passing, they erase themselves as counterexamples, leaving those unable or unwilling to pass as the basis of the public's perception of gay men.

Victims obviously aren't to blame for the fact that people rely on stereotypes and snap judgments, but according to this second objection to passing, victims do influence the content as well as the apparent reliability of stereotypes when they decide to pass. And since these stereotypes cause real harm by serving as the basis for oppressive treatment, individuals might owe it to their fellow victims not to pass. While Mills held that deception in itself doesn't make passing wrong, she does argue that "when oppressive social patterns determine who needs to pretend, this is deeply disturbing, morally. Where there is injustice, we all have a duty to combat it rather than to cooperate with it by reinforcing its institutions and expectations" (1999: 48). Similarly, Cooley argues for a moral 
obligation to out oneself when doing so doesn't "pose a significant danger to a person's flourishing life" and when there's a reasonable chance that "at least one person will become more accepting of homosexuals than if the person remained closeted" (2012: 48, 50). For Cooley, the greater the potential impact of outing oneself, the stronger the duty to do so (2012: 50).

In addition to reinforcing stereotypes, passing can also increase the pressure on one's fellow victims to conform to oppressive expectations. After all, passing doesn't just affect who's seen as an $x$-it also affects where members of $x$ are seen, what they're seen to enjoy, and so forth. When only some members of $x$ are visible, their responses will be taken as representative, and expectations will form on the basis of their behavior. If those who would object to an oppressive expectation are instead passing to escape its impact, then the reduced level of pushback might be taken as evidence that the expectations are reasonable, or even preferred. Mills explains the point thusly:

The central other-regarding issue here concerns the way in which an individual's presenting herself in a certain way to achieve societal acceptance can reinforce unfairly discriminatory or oppressive social norms that would better have been challenged directly. If I revise my selfpresentation to accommodate a social norm, this puts additional pressure on others to do so as well. (1999: 47)

This cycle parallels Ann Cudd's (1994) 'oppression by choice' scenario, where individually rational decisions by victims aggregate in a way that reinforces oppressive institutions, resulting in harm to one's fellow victims.

There is a final way in which passing can reinforce stereotypes. When fellow group members are aware that an individual is passing, they can feel pressure to keep the secret rather than outing him against his wishes. Not only might this force fellow victims to tell corroborating lies, but as Richard Mohr contends, it forces them to reinforce the notion that the identity in question is one worth lying about. If the dominant culture considers being gay a shameful identity, then by pressuring other gay people to help conceal his identity, the passing person is essentially "requiring the other gays to degrade themselves as gay, to sink to the level of abjection dictated for gays by the dominant culture" (Mohr 1992: 30). According to Mohr, keeping another's "dirty little secret" does an injustice to oneself, because it involves "going along with rather than resisting the values that oppress gays" (1992: 31). After all, the identity in question isn't unique to the passing individual - it's shared by the very persons who are now pressured into reinforcing the view of homosexuality presupposed by the secret (1992: 32f.). This is why Mohr believes in an obligation to out closeted individuals against their wishes, in all but the most vulnerable of circumstances. To keep the secret 
is to give up one's "own dignity for the happiness of the closeted gay person," and that's an inversion of how we ordinarily understand moral life, "in which nobility of character ... lies in sacrificing one's happiness so that dignity-one's own or others' - might be asserted" (1992: 33).

While these are all serious concerns, I suspect the 'reinforcing' objection to passing overestimates the influence that victims can have on the content or longevity of stereotypes, even without considering the nearby collective action problem. There's simply no guarantee that a stereotype will actually change if more members of $x$ allow themselves to be seen as an $x$-stereotypes aren't careful, truth-tracking judgments that readily give way to new and conflicting evidence. The result of increased visibility might just be more targets for the stereotype. Worse, epistemic dominance often ensures that victims' actions and utterances come predefined. Consider how public protest by racialized minorities can reinforce stereotypes about their inherent lawlessness and dangerousness, or how complaining about a sexist joke in the workplace can end up reinforcing stereotypes about women being humorless and hostile overreactors. If even resistance can be interpreted as support for the very stereotypes being resisted, then the decision between passing and merely making oneself visible is unlikely to have much of an effect on oppressive assumptions and attitudes.

Along the same lines, there's also the chance that allowing oneself to serve as a visible counterexample will lead to tokenism rather than stereotype change, thus reinforcing whatever stereotype visibility was meant to combat. Suppose someone makes a homophobic generalization around a group of coworkers, and a gay man who'd been passing as straight up until that point responds by saying "You know what? I'm gay. Not all gay men are like that." For the moment, let's leave aside the personal risk he takes in outing himself, and focus on the attempt to undermine the stereotype by making himself visible. It's certainly possible that the original speaker or other coworkers will learn from the episode, and broaden their conception of gay men accordingly. Cooley's version of the obligation to out oneself is grounded in just that sort of small-scale change. But it's also possible the fellow's coworkers will see him as an exception to the rule, or as an example of the 'good kind' of gay man - the sort that doesn't flaunt his identity or demand special treatment. We can imagine a coworker countering: "I have no problem with people like you! Normal guys who just happen to be gay. It's those flamboyant ones. Why do they have to be like that? I mean, you're not. So they must be choosing to act that way ..."

If the 'reinforcing' objection states that passing is wrong because it puts additional pressure on fellow victims, then we need to consider the possibility that not passing can have the same result. In the above exchange, opting for visibility marginally increased the covering demand on other gay men to act 'normally', and reinforced the sense that something is abnormal about identity expressions 
that fall outside of mainstream view. Where Mohr's argument runs into complication is that group members have to contend with more than one pressure and more than one stereotype. While keeping secrets can reinforce the dominant culture's attitude that a given identity is shameful, the tokenism example shows how outing oneself can have the unintended consequence of also making the identity more shameful for those who share it. Under conditions of epistemic dominance, we should expect double binds, and be wary of formulating obligations that don't account for them. ${ }^{14}$

Perhaps then, it was a mistake to respond to the coworker in our example by saying "Not all gay men are like that." Perhaps the employee should have directly challenged the notion that there's anything abnormal about the targets of the homophobic comment, or criticized the heteronormative attitudes underlying it. But notice that sort of resistance doesn't require the gay employee to make himself visible. Progressive messages can be delivered by anyone, and might even have more force coming from someone the original speaker wouldn't expect, like a 'fellow' straight person. After all, when the target of a stereotyping comment complains, they're often dismissed as self-interested or overly sensitive, as with the 'humorless feminist' trope mentioned above. But when a (supposed) member of a privileged group objects, their complaint can be harder to dismiss, and may in fact be lauded for bravely raising an issue that those affected have actually been raising for, well, quite some time now. Passing victims can discharge their obligation to challenge stereotypes by means other than visibility, and that makes a focus on visibility reductive.

Samuels outlines another unintended consequence of demanding visibility: given the particulars of certain identities, the only way for some individuals to make themselves visible enough to notice might be to emphasize identity markers that are themselves stereotypical. Discussing the tendency for invisible disabilities to be disbelieved, she notes that many people who have them "face not only uneasy inclusion in the disability community but a daily struggle for accommodation and benefits that reflects the dominant culture's insistence on visible signs to legitimate impairment" (2003: 245). She gives the example of someone intentionally bumping into a wall in order to satisfy scrutiny about whether she's really blind (2003: 247), and we can imagine the same pressure leading someone with chronic pain to feign a limp when using a reserved parking spot, or someone with depression to act out false symptoms of overt sadness that films have conditioned

14. Mohr's contention that group members have an obligation to out closeted individuals is beyond the scope of this paper, which explores the question of whether victims should pass in the first place. That said, I don't think the purported wrong of drawing another into a secret is significant enough to affect a victim's decision about passing. The claim conflates pressure to keep a secret with being forced to do so, and also places the blame for that pressure on the victim trying to escape oppressive circumstances instead of on the circumstances themselves. 
the public to expect. This is why Samuels cautions against making visibility "the basis of community and the means of enacting social change": rather than valorizing coming out and condemning passing as assimilationist, the invisibly disabled can be better helped by resisting the assumption that appearance and identity are correlated (2003: 244). She explains that many invisibly disabled people feel their choice "is between passing and performing the dominant culture's stereotypes of disability," and if she's right, then they're caught in a double bind that involves reinforcing a stereotype either way (2003: 247).

The example above is another demonstration of how traditional arguments against passing fail to accommodate the diversity of identities, circumstances, and individual differences. Passing doesn't straightforwardly reinforce stereotypes, and visibility doesn't necessarily weaken them. The effect is too contingent to condemn passing on these grounds, especially when we stop bracketing the personal risks that victims take in outing themselves, and restore those risks to our analysis. Even if making oneself visible reliably undermined stereotypes by some amount, the harm victims expose themselves to by not passing can easily outweigh whatever marginal contribution their passing would have had on the strength of the stereotype.

\section{$3 \cdot 3$.}

Although passing victims don't straightforwardly contribute to the oppression of their own group, some theorists argue that they do little to stop it, either. The third other-regarding objection is that passing is wrong because it means opting out of the shared struggle to end oppression. I consider this to be the most interesting otherregarding challenge, as it amounts to the claim that victims are wrongly looking out for themselves in circumstances where their obligation to others is greater.

This is the position Mills was building toward when she talked about reinforcing oppressive norms that should have been challenged. Passing isn't intrinsically wrong, in the sense of being inauthentic or the like-it's wrong because it involves hiding when the situation calls for fighting. She writes:

I have no particular obligation to present my "true" self to others . . But where pretense and self-transformation are occasioned by the fact of oppression, one owes it to oneself and to society-and most of all to fellow members of oppressed or unfairly burdened groups - to fight back against oppression and unfairness directly, rather than simply minimizing its costs to oneself. (1999: 30) ${ }^{15}$

15. She considers this obligation weaker than the collective obligation to work against oppression. 
This is also Stone's major criticism, in that passing as cis is functionally incompatible with a trans person's ability to resist the gender binary that robs them of a place. Stone argues that "it is difficult to generate a counterdiscourse if one is programmed to disappear. The highest purpose of the transsexual is to erase him/herself, to fade into the 'normal' population as soon as possible" (1992: 164). In a later passage, she movingly describes the obligation to do more than look out for oneself:

I could not ask a transsexual for anything more inconceivable than to forgo passing, to be consciously "read," to read oneself aloudand by this troubling and productive reading, to begin to write oneself into the discourses by which one has been written ... I ask all of us to use the strength that brought us through the effort of restructuring identity, and that has also helped us to live in silence and denial, for a re-visioning of our lives. I know you feel that most of the work is behind you and that the price of invisibility is not great. But, although individual change is the foundation of all things, it is not the end of all things. (1992: 168)

According to Stone, the problem with passing is that the struggle isn't yet over.

Harrison takes a related position when it comes to passing as straight, which she argues is at odds with one's integrity and identity as a member of the LGB/Q community. She discusses the importance of homonormativity, which "refers to a system of moral and ethical thinking that is developed to address the needs of people who enter into same-sex relationships. When people choose to pass, they are choosing to engage in heteronormativity" instead (2013: 169). And this passing is incompatible with their Korsgaardian practical identity (meaning: the description under which a person values herself, her life, and her actions), since heteronormativity undermines the humanity and autonomy of gay women and men. Harrison elaborates:

Gayness as a practical identity creates obligations to others through our shared commitment to the political ends of the LGB/Q community. It allows for reciprocity in our friendships, love relationships, political coorganizers, queer co-workers, queer mentors, and queer social leaders. The key commitment that must arise first and foremost to guarantee these relationships of reciprocity is an open commitment to the practical identity of gayness. Passing, in this regard, is the most significant threat to relationships of reciprocity and responsibility for the LGB/Q community. (2013: 173) 
Once again, we see the idea that passing represents more than an escape from oppression-it's an escape from the kinds of relationships and resistant activity that victims owe each other.

Passing can even raise questions about the fair division of burdens, since some members of oppressed groups have little ability to pass, and are thus subject to being abandoned to oppressive treatment and resistance work when those who can pass choose to do so. To recall previous examples, a person with poor visual acuity or low vision can pass as fully sighted during typical encounters with others, but a person with profound visual impairment is unlikely to pass for long, given the recognizability of mobility aids and other cues. Similarly, someone with very dark skin will probably not pass as white, and that means contending with oppressive burdens that a lighter-skinned member of the same group can avoid. Given that not everyone has the opportunity to opt out, passing as privileged can erode relationships of solidarity.

These kinds of evaluations of passing are common. But I think we need to examine the purported connection between passing and inaction more carefully. First, passing as privileged doesn't necessarily entail abandoning one's community, and can even be compatible with engaging in acts of resistance. MacLachlan acknowledges that coming out can be one avenue for resisting oppression, but notes that this falls short of the stronger claim that "coming out is a necessary part of resistance," which would require one to show "either that no other forms of resistance are possible for the non-out individual or that remaining closetedwhatever else one does - so strongly indicates passive submission to oppression that it effectively nullifies all other acts of resistance" (2012: 313). But as was mentioned in Section 2, victims sometimes pass in order to better understand oppressive institutions, marshal resources, or create opportunities for those that will inevitably follow them. Passing can also allow a victim to avoid scrutiny, thus freeing her to engage in more effective resistance later on. And for that matter, not every form of resistance requires public confrontation. An individual can pass at work or in other spaces constrained by privilege, while still openly organizing on a community level, or offering emotional support to those who live the fight in more direct ways. Trying to escape the worst of oppression doesn't rule out relationships of reciprocity, and it doesn't mean that the struggle isn't being shared.

The last point about passing in some domains while expressing solidarity in others is important. The 'opting out' objection seems to assume that passing victims are separating themselves entirely from oppressive contexts, in effect leaving their 'old lives' behind. But not every passing victim chooses to pass completely. Passing can be situational and context-dependent, and is often just one part of a broader strategy for navigating oppressive circumstances. MacLachlan argues that for many queer people, 
managing one's identity in a heterosexist society is a matter of degree: how and when to continue disclosing, how much to "cover" or minimize one's queerness for the comfort of others or to avoid distraction, and when to shock, maximize, reclaim, and disrupt for strategic political purposes. (2012: 326)

Yoshino puts the point even more bluntly, writing “Every gay person I know passes on occasion," and argues that attacking those who hide at politically crucial moments "is an internalization of homophobia, in which we criticize the gay person for passing rather than the antigay institution that commands him to do so" (2007: 64). And Brennan reminds us that the need for greater visibility doesn't translate into a criticism that passing individuals are failing to resist:

There are degrees of "out" and degrees of "visibility" and negotiating these degrees does not automatically make one a coward for failing to reveal all aspects of one's identity. This shows a tension between visibility as an individual strategy and visibility as a political issue. We might want to raise awareness about sexual minorities without always insisting that the best route to doing this is by having individuals come forward. And if they do come forward the burden of recognition, of explanation, surely ought not to fall on individuals alone. (2012a: 197)

Even 'selfish' passing done entirely for one's own gain is still compatible with resisting oppression and fulfilling one's other-regarding obligations. As Adrian Piper relates,

many of my more prominent relatives who are passing have chosen altruistic professions that benefit society on many fronts. They have chosen to use their assumed social status to make returns to the black community indirectly, in effect compensating for the personal advantages they have gained by rejecting their family. (1996: 244f.)

And such contributions make a difference. So while there might be a case to make that victims who abandon their obligations to others are impermissibly opting out of a shared struggle, we can straightforwardly deny that passing as privileged functionally amounts to abandoning one's obligations. In fact, it takes a rather strong other-regarding obligation to conclude that victims must endure oppression that they have an opportunity to escape.

There's a second reason why we need to be careful about asserting a connection between passing and inaction. It's not just that passing is compatible with acts of resistance and relationships of solidarity. The 'opting out' objection 
also builds in the assumption that fighting back against oppression is a victim's most important and pressing obligation. If you're not resisting, then you must 'merely' be looking out for yourself, in the pejorative sense of the phrase. But that doesn't follow, either.

Suppose someone is a lesbian or bi, but is more interested in working to stem the tide of global climate change. Perhaps her skill set enables her to do more good as an environmental attorney than she could have done as a civil rights activist. Or perhaps she simply finds that kind of work more intellectually stimulating. Now suppose that passing can help her rise in the relevant organizations, or make her a less controversial public advocate. Is she doing wrong by dedicating herself to one kind of social change at the expense of another, one that doesn't directly benefit members of her group? ${ }^{16}$ What if instead of drafting climate treaties, she spent her time working on child hunger, or sex trafficking, or reparations for historically oppressed populations? She may be opting out of the struggle against heteronormativity, but she isn't passing in order to minimize the costs of oppression to herself, any more than a man who passes in order to secure a privileged future for his children is 'merely' looking out for himself. And even if the environmental attorney is failing her fellow victims by opting for a different political struggle, it's not clear why she must principally identify with her own subordinated group, let alone owe an obligation of resistance to its members strong enough to override whatever she owes to other folks in need. Oppression can create obligations for the oppressed, but these aren't a victim's only other-regarding obligations. And when it comes time to balance competing obligations, it doesn't make sense to treat her membership in a group as a decisive other-regarding consideration. We should be cautious about suggesting that being a member of a subordinated group is sufficient to order one's ethical priorities.

The next step of the response is to ask whether the above reasoning only applies to competing other-regarding obligations, or if certain self-regarding obligations can also give a victim a good reason to opt out of a shared struggle, without her thereby being guilty of 'merely' looking out for herself. If the obligation to sacrifice on behalf of one's fellow victims is not an absolute, and can be outweighed by other moral undertakings of sufficient importance to an individual, then prioritizing weighty struggles of a more personal nature should also be permissible-especially if those personal struggles are born of oppression. After all, it's strange to conclude that being oppressed creates obligations to look out for one's fellow victims, but doesn't create any obligation for a victim to look out for herself.

16. Of course, it's often possible to resist more than one injustice at a time. I'm deliberately considering a case where an agent chooses not to, or at least chooses not to include her own oppression among her priorities. 
And if passing can be a permissible means when helping others, it's at least possible the same holds true when contending with the burdens in one's own life. Consider a woman who dreams of advancing in a sexist but otherwise rewarding field. Or someone in a vulnerable position, whose reputation and relationships both depend on concealing his stigmatized anxiety. Or the father mentioned above, who hopes his children will grow up free of the injustices he had to endure as a child. These individuals are not 'merely' looking out for themselves, if what's meant by the phrase is acting with indifference to oppressive harms. Their decisions to pass are very much attempts to contend with those oppressive harms.

When an individual faces fundamentally unfair burdens, trying to live the life she wants is one form the struggle against oppression can take. To put the point more formally, given that oppression interferes with constituents of wellbeing such as worthwhile relationships or valuable plans and projects, protecting those relationships or actively pursuing those plans is more than a selfish minimization of costs: by refusing to accept the limitations that oppression imposes, these agents are discharging genuine, self-regarding obligations. Likewise for other constituents of well-being that passing can facilitate, such as physical and material security, happiness, expanded autonomy, and so on.

The phrase "looking out for yourself" has both negative and positive connotations. It can be a term of reproach for victims that shirk their obligations or minimize costs to themselves at the expense of others. But it can also be a term of praise for agents that take care of themselves in circumstances that threaten their well-being, who strive to live the life they want despite the burdens they encounter. When we just weigh other-regarding obligations against each other, we're not fully engaging with a victim's agency or circumstances. If we want to evaluate the permissibility of looking out for oneself in times of shared struggle, then we also have to consider what victims owe to themselves. And if they owe it to themselves to escape oppressive mistreatment, then it's likely passing is more than a simple shirking of one's obligations.

Having argued against the three main other-regarding considerations, I now turn to the question of what, if anything, passing victims owe themselves.

\section{Self-Regarding Considerations}

Unlike the uniformly negative considerations canvassed in Section 3, selfregarding considerations factoring into the permissibility of passing are predictably mixed. In the introduction, I argued that passing as privileged is a strategy for dealing with unjust barriers and burdens, and shares at least one aim with resistance: namely, improving one's life or circumstances in the face of oppression. 
It is, in other words, an attempt to look out for oneself. So how does that strategy fare? There are three answers: that passing is unproblematic because it's a form of successful resistance, that passing is impermissible because passing victims have to give up too much, and finally my own view, which occupies something of a middle ground - that passing is typically a permissible but limited strategy because it advances well-being through complicity in one's own oppression.

4.1.

Given that our discussion of the 'opting out' objection ended with the possibility that passing is actually a way of struggling against oppressive barriers and burdens, it makes sense to begin with the claim that passing is unproblematic because it's a form of self-regarding resistance to oppression. Passing victims are, after all, victims, so an attempt to minimize one's own oppression is straightforwardly an attempt to spare at least one person from victimization. If stigmatization makes it unfairly difficult to pursue valuable life plans, then pushing ahead with those plans is a form of resistance. If discrimination undermines security, then protecting yourself is a form of resistance. And so on. Where injustice interferes with constituents of objective well-being, valuable external goods, capabilities, flourishing, or however else one wants to understand morally worthwhile lives, attempting to live that morally worthwhile life anyway is an act of resistance.

Having elsewhere advanced a self-regarding obligation to resist oppression, I'm sympathetic to this line. In fact, even other-regarding critics of passing acknowledge that it can spare victims some degree of oppression. Their objection is that passing victims should care less about minimizing their own oppression, not that passing victims are unsuccessful. So unless victims only discharge their obligation to resist when they minimize someone else's oppression, passing is at least plausible as a resistance strategy.

Indeed, the fact that passing victims enjoy the benefits traditionally reserved for privileged individuals could make passing a doubly subversive act: not only are they sparing themselves some of the burdens of oppression, but they're also redistributing undeserved advantages away from their oppressors. Piper, who likens passing to cauterizing oneself (1996: 244), concedes that

Once you realize what is denied you as an African American simply because of your race, your sense of the unfairness of it may be so overwhelming that you may simply be incapable of accepting it. And if you are not inclined toward any form of overt political advocacy, passing in order to get the benefits you know you deserve may seem the only way to defy the system. (1996: 244) 
Even if we stipulate that overt political advocacy and direct forms of conflict are always better strategies for looking out for yourself under conditions of oppression - and I'm honestly not sure they are-that doesn't necessarily mean hiding from oppressive treatment by passing isn't a resistance strategy on its own terms.

While I'm sympathetic to these kinds of considerations, I think we should be careful about conflating acts that simply help oneself with acts of genuine resistance. It's not enough that victims improve their burdened well-beingotherwise, notorious examples of non-resistance would have to count, including outright collaboration with one's oppressors. If someone reveals the location of the next underground meeting, and is paid handsomely for the mass arrests that follow, we can admit that the collaborating victim is better off without agreeing that they resisted their oppression. To count as resistance, the self-regarding activity has to come into conflict with oppression in some way. It should be an attempt to undermine, change, or escape the oppressive system that constrains the victim, rather than an attempt to curry favor by deepening one's connection or dependence on that system. The special treatment collaborators receive is not an escape from oppression: it's their reward for participating in it.

Collaboration is obviously an extreme example, one that involves direct engagement with the forces of oppression against the members of one's own group. Are more commonplace examples of helping yourself without bringing yourself into conflict similar in kind, if not in degree? I think they often are. Imagine a bullied teenager who escapes mistreatment by showing up on the first day of the new school year dressed in the same fashions as his tormenters, expressing interest in the same music and sports teams they do, laughing at the same jokes they enjoy, and the like. Say he distances himself from his old crowd, and even cheers the bullies on when they humiliate a similar target. The bullies eventually accept him, and begin to treat him like they treat each other. Now, did acting like his tormenters reduce his suffering? Certainly. And we can readily understand why he'd consider his newfound peace well worth the loss of a little self-respect and the friendships he left behind. The question is whether this respite is the result of resisting his bullies. And whatever else we want to say about his strategy, the answer has to be 'no'. He didn't challenge their values, or attempt to nudge their behavior in a different direction. The bullying stopped because he joined his bullies-because he managed to change his position on the social hierarchy, and was treated accordingly.

The logic of this example parallels passing as privileged. While passing victims successfully minimize some of their burdens, this minimizing is no more an act of resistance than the everyday conduct of privileged group members who also escape the burdens of oppression by looking, dressing, and acting a certain way. As Harrison puts it in her discussion of sexuality passing, "Some 
persons are rewarded for authenticity: monogamy driven heterosexuals. Others are rewarded for passing: everyone else" (2013:3). Passing doesn't automatically bring a victim into conflict with oppressive norms or institutions, nor does it allow victims to escape the double binds that created the pressure to pass in the first place. To the extent that passing is successful, it's because victims blend into non-oppressed groups and are held to non-oppressive standards of treatment. Passing can improve a victim's well-being. For that reason, passing is permissible. But that doesn't make it an unproblematic form of self-regarding resistance.

At this point, one could object that blending into a privileged group isn't always an attempt to resist qua escaping oppressive treatment. Instead, the resistance could be about defying external pressure to conform to stereotypical traits. Victims shouldn't need a special justification to style their hair a certain way, or to adopt a particular manner of dress, or to enjoy a hobby that's more popular among other groups than it is among their own. Everyone else enjoys a presumption in favor of freely expressing their individual identity, and if you're a victim, the possibility of confusing others about your identity shouldn't be enough to outweigh that presumption, let alone trigger an obligation to compulsively disclose your 'real' identity. A victim who passively blends into a privileged group by expressing herself isn't just exercising her agency, or engaging in valuable self-discovery and self-definition - she could be actively resisting the norms and expectations that seek to constrain her self-expression.

Against this point, some authors claim that passing can't be an instance of self-expression because passing is, by definition, adopting an identity other than your own. For example, in her discussion of sexual identity passing, Harrison deems it a kind of sexual deceit, which "firmly suggests an infidelity to oneself and one's identity" (2013: 2). And Mills contends that the chief self-regarding issue of passing is

whether the proposed presentation of myself involves some fundamental dissonance in my own view of myself, so that I myself feel that in presenting myself in this way I am betraying or alienating some central facet of who I am. (1999: 43)

But my position throughout this paper has been that we should avoid analyzing the permissibility of passing by appealing to questions of authenticity. We've canvassed too many cases, like queer femmes or those with invisible disabilities, where being authentically yourself is what triggers passing, while attempting to make your identity clear to others would require deviating from authentic selfexpression. I think we should grant that being yourself is sometimes compatible with passing. Besides, I want to take seriously the idea that at least in some cases, passing can be a legitimate step in a process of self-transformation, like when a 
victim of stereotype threat passes as a confident professional in an attempt to 'fake it until they make it'. ${ }^{17}$

So, is being yourself, in defiance of oppressive expectations, a form of resistance? I'm inclined to think so. But it's not the kind of unproblematic resistance that would immediately settle the value or self-regarding permissibility of passing as a whole. Given the ways that identities, preferences, social locations, and the like are policed in oppressive circumstances, embodying an authentic identity that causes you to passively pass will expose you to significant risks and costs. Fellow victims might think you're distancing yourself. Privileged individuals might think you're tricking them, and punish what they wrongly take to be a deception. You may have to constantly explain your identity, and defend the legitimacy of your self-expression while others use their epistemic dominance to reject the authenticity of your performance. You will likely face the double bind of external pushback for being yourself or punishing yourself for conforming to the identity others expect of you. Defiant self-expression doesn't escape the problems of passing, for all the reasons that passive passing usually tends to be unsustainable in the long run.

\section{2.}

The second self-regarding consideration veers in the other direction. Some argue that even if victims do gain a few benefits through passing, the price will always be too high, or involve some aspect of identity or the good life too central to trade away. Or that the benefits of making oneself visible will reliably prove more valuable or more central than whatever passing can offer a victim. Passing just can't deliver enough, or what really matters. In short, these views argue that the relative costs of passing make it an impermissibly self-undermining strategy.

We've already seen Mohr claim that whatever happiness or security is gained by keeping one's sexuality a secret will come at the expense not only of one's own dignity, but the dignity of any gay man or woman forced to go along with that secret. And Mohr isn't alone in considering the trade-off to be reliably disadvantageous for victims. In the previous subsection, I mentioned Piper's claim that passing is akin to cauterizing oneself. Her examination of the trade-offs involved in racial passing is incredibly illuminating:

At the most superficial level, this decision can be understood in terms of a cost-benefit analysis: Obviously, they believe they will be happier in the white community than in the black one, all things considered. For me to make sense of this requires that I understand-or at least accept-their

17. My thanks to an anonymous referee for this example. 
conception of happiness as involving higher social status, entrenchment within the white community and corresponding isolation from the black one, and greater access to the rights, liberties, and privileges the white community takes for granted. What is harder for me to grasp is how they could want these things enough to sacrifice the history, wisdom, connectedness, and moral solidarity within their family and community in order to get them. It seems to require so much severing and forgetting, so much disowning and distancing, not simply from one's shared past, but from one's former self-as though one had cauterized one's long-term memory at the moment of entry into the white community. (1996: 244)

And for Mills, the steep price of passing is part of why she finds these cases so disturbing: "often the choice to pretend or to change oneself is enormously costly for the individual. It may buy her some comfort or security, but only at the sacrifice of her dignity, of her very selfhood" (1999: 44).

Mohr, Piper, and Mills all acknowledge the existence of benefits, but cite authentic selfhood, dignity, and community as prices too extravagant to pay. Some advance similar arguments about autonomy and agency being among the costs of passing, which would be uniquely worrisome insofar as costs like those tend to wipe out any gains that are made. Marina Oshana begins her discussion by noting that "Passing' is a euphemism for 'death"', and that "people who pass attempt, at some level, to declare dead some key element of their identity" (2010: 63). She concedes that forgetting oneself can be prudent and even empowering in some contexts, like female authors adopting male pen names in earlier centuries, but she considers many attempts at racial passing to be tragic because of the centrality of what's lost:

the item one wishes to forget is typically of monumental import to a person's self-image. One does not attempt to pass, to imprison, or to reinvent something that is of minor concern to her. People don't seek cosmetic surgery unless they feel strongly about the visage they seek to alter. People don't adopt false identities, complete with assumed names, unless they have some strong reason to not be known as they were. What one wishes to shed is something that occupies a central and essential a role in one's identity - if it weren't so essential, one could easily ignore it. $(2010: 65)^{18}$

18. I'm not sure this characterization is correct. Some victims pass not because those aspects of their identity are central or even all that salient to their self-image, but because everyone else is so hung up on them that it's interfering with the victim's ability to live the life they want. We can't assume an individual has strong feelings of revulsion or alienation simply because they find their identity difficult to ignore. 
According to Oshana, the cost of leaving something that essential behind can affect "a person's ability to manage their life, as unified agency requires" (2010: 66).

Taking up the example of Anatole Broyard, Oshana writes that

certainly, Broyard's conceptual, interpersonal, and, perhaps, private selves were fractured because of the lie he was living, with the result that authenticity was improbable. ... Broyard's agency, notably with respect to his success in achieving the goal he had set for himself as a writer, was diminished because he denied the salience of an essential identityforming aspect of his life. (2010:67)

In other words, the cost of passing proved corrosive to the project it was meant to facilitate, because alienating himself from his identity made it impossible to write from a place of authenticity and truth. By passing, Broyard undermined his own autonomy.

Natalie Stoljar resists this conclusion, arguing that passing can actually increase autonomy, if we distinguish autonomy from authenticity. An agent can fail to be true to herself, in the sense of embodying a practical or social identity that is her own, while still being true to herself in the sense of being free in her selection and pursuit of aims that are her own (ms: 2). Despite Broyard's failure to fulfill his aims, his inauthenticity still served to increase his autonomy:

In passing for white, Broyard managed to liberate his will (and his action), at least to some extent, from the socially prescribed script that would have applied to him as a black man. Because he was light-skinned, he was able to fit himself under a different social classification, and he became freer with respect to his options for willing as a result. He was able to make his goals and life-plans more his own (in the second sense) by enhancing his control over the possibilities available to him. (ms: 17f.)

For our purposes, the implication of this exchange isn't that essential goods like autonomy are safe from the kinds of trade-offs that passing victims are forced to make. Some victims may well sacrifice their autonomy, and some of those who do will stumble in their pursuits as a result. But the vital good of autonomy isn't always a cost of passing, permanently tipping the scales toward impermissibility.

Nor is the trade-off as bleak as authors like Mohr imagine it. Halwani responds to Mohr by arguing that dignity isn't the only virtue at stake in decisions about whether to keep secrets. Dignity, pride, and self-respect can all incline one toward outing, but sympathy, compassion, benevolence, and even justice can count in favor of abiding by the secret (2002: 144, 147). And the same is likely true of Piper's claims about community and selfhood. Examining cases where 
victims pass completely can paint a stark picture about the costs of passing, but given how many aspects of the good life can be tied up in a decision about whether to pass, and the different extents to which individuals choose to pass, it's doubtful that the costs will always be higher, for all victims, across all imaginable circumstances. Who a person is, what constitutes her conception of the good, how much her aims depend on passing, and what she can painlessly live without all have an effect on whether passing presents a net negative trade-off.

Instead of arguing that passing always carries a cost too vital to pay, many authors emphasize just how many components of the good life can be gained by outing oneself, or living visibly as a member of a subordinated group. Chekola, for instance, counts integrity and connection among the goods of honesty. He writes that "Integrity can be understood as involving honesty and forthrightness and a disposition to stand up for what is right and not being tempted by the easy path," which is why passing - the purported easy path for victims-involves "some loss of integrity" (2012: 20). Likewise, victims have more to gain from honesty because of how much relationships depend on it:

since passing involves hiding information about oneself from others, it impairs relationships, both casual and close, and fosters isolation. Even casual relationships, such as those among coworkers, involve some sharing of information about one's life. The level of intimacy of a relationship is determined by how much of his self a person reveals. (Chekola 2012: 20)

According to Chekola, if a victim values integrity and connection, then those goods are better pursued by not passing.

Writing within the virtue framework, Cooley sees an even greater variety of benefits coming of the decision not to pass. It can offer connection, in the sense of improving relationships: "In many cases, being out will enhance the person's flourishing by allowing her to create and nurture caring relationships that would otherwise be denied to her whilst she is closeted" (2012: 48). But it can also offer connection in the form of solidarity:

being out allows an agent to share an important, if not essential, characteristic with others so that true friendships and other positive relationships can be built on the trust and communication that is denied to those who are closeted or veiled. (2012: 48)

Forgoing the option to pass can also protect one's health and security. Cooley writes of 
the sheer relief gained by eliminating the mental strain caused by maintaining a closeted life, e.g., having to ensure never giving oneself away in conversation or other actions, and remembering which lies were told to which people. (2012: 49)

Outing oneself can increase a victim's self-respect, insofar as "there is an end to denying one's identity, the latter of which causes shame, degradation, and inadequate self-esteem and integrity" (2012: 49). And, of course, happiness: "By being honest, the benefits can go a significant way in improving a person's happiness, and therefore flourishing" (2012: 49). The list goes on (2012: 48f., 61), but the point is clear: passing seemingly can't offer a victim the same life that outing oneself can.

I don't deny that visibility can have these benefits. In fact, my own argument will appeal to the many trade-offs involved in passing. But just as it was a mistake to assume that passing is always the costlier choice for victims, arguing that visibility is always better is insufficiently sensitive to the diversity of identities, circumstances, and individual differences that comprise the phenomenon of passing as privileged. Sure, some passing victims might fare worse for the trade, and some may even suffer dramatically, but if the structure of well-being and oppressive circumstances were such that visibility was always better for victims, then we'd be committed to the idea that passing victims are fundamentally irrational. There'd be no need to debate the permissibility of passing because every victim attempting the strategy would be mistaken about how to improve their lives. And I'm not convinced they are mistaken. We've considered many examples where passing helped a victim come out ahead. Some victims gain, some victims lose, and given the nature of double binds, even the victims who gain pay some kind of cost or face some kind of risk. Passing as privileged is simply too complicated a phenomenon to support overgeneralized verdicts about how the lives of passing victims will go overall.

If we want to evaluate passing as a strategy for protecting and promoting well-being, and have the argument apply to the truly varied collection of individuals who decide to pass across such genuinely distinctive circumstances, then we can't claim passing always involves a particular trade-off, or that the trade-off involved is always disadvantageous. We need an account that's flexible in its characterization of these trade-offs.

$4 \cdot 3$.

This brings us to the third and final self-regarding consideration, namely that while passing can be advantageous for victims, and is thus permissible to do, it's nonetheless a structurally limited strategy for protecting and promoting a 
victim's well-being because the beneficial trade-offs depend on being complicit in one's own oppression. This is the position I myself advance, and it offers a middle ground between the idea that passing is straightforwardly beneficial and the idea that passing is so costly that it's a fundamentally self-undermining strategy. On my view, passing as privileged is indeed a way of looking out for yourself. But it's a structurally limited way of doing so. Mind, I don't think this is a definitive consideration, or one that applies evenly across all cases of passing as privileged. As should be clear by this point, I don't think any consideration has that kind of reach, or that we should even be looking for a comprehensive verdict to begin with. But I do think this consideration comes the closest to fairly capturing the strategy of passing as privileged, at least pending a more robust ethics of looking out for yourself.

Given my commitment to accommodating the diversity of identities, circumstances, and individual differences that make up cases of passing, the strategic limitation I'm pointing to can't be tied to the loss of any particular constituent of well-being like connection or purported good like authenticity, nor can it depend on a stacked calculus where whatever victims happen to lose always comes out weightier than what they attempt to gain. Setting aside blunders and bad luck, I grant from the outset that passing is generally advantageous for victims, and may even be the most advantageous option in some situations. What makes passing a limited strategy will have to do with the nature and structure of the trade-offs themselves, not with the outcome of some cost-benefit analysis.

The fact that victims are presenting themselves as privileged, in particular, also can't account for why passing as privileged is problematic. For one thing, that would mistakenly indict some identities at the margins, like queer femmes and people with invisible disabilities. But it would also make it hard to explain why victims are doing something uniquely complicit by wearing the clothes that privileged individuals also wear, by acting the ways that privileged individuals also act, and so on. The only way to explain the difference then would be to appeal to the pretense involved: enjoying the privileges that come with, say, 'sounding straight' is fine if that's how you naturally talk, but if it's not, then the deception morally taints your enjoyment of those goods. ${ }^{19}$ But I've maintained throughout this paper that we should move past the deception/authenticity framework. So instead of claiming that presenting yourself a certain way is what makes you complicit in oppression, I'll argue that the strategy of improving your well-being by passing depends on the continued existence of the oppressive system that's constraining your well-being in the first place, and that this dependence is what makes you complicit in your own oppression. Passing is a limited

19. I thank an anonymous referee for helping me clarify this portion of the argument. 
strategy because it doesn't challenge the constraints on your well-being -it just exploits the manner in which those constraints are distributed.

Stepping back, I think there are really two varieties of victim complicity, one other-regarding and one self-regarding. The more familiar of the two, otherregarding complicity, occurs when an individual participates in, passively allows, or benefits from a system that harms others. This is the kind of complicity most associated with members of privileged groups, as their visibly apparent identities automatically single them out for advantageous treatment in oppressive circumstances. But victims can also be complicit in the oppression of their fellow victims. Cases include collaboration, reinforcing stereotypes that limit one's own group, and legitimizing oppressive forms of treatment by staying silent or seeming to prefer them. When Mills objects to passing, she has other-regarding complicity in mind: "our moral evaluation of passing under circumstances of oppression should turn on the extent to which we view passing as actively collaborating with injustice, rather than merely failing to resist it" (1999: 49). Ditto Chekola, who claims that the "passer reinforces the oppressive structure for his own personal gain or ease" (2012: 20). It's also the danger that Claudia Card points to in her characterization of moral gray zones. Card argues that "One of the greatest evils threatening victims of oppression is the danger of becoming evil oneself, becoming complicit in evils perpetrated against others" (1999: $3 \mathrm{f}$.).

My account doesn't depend on claims of other-regarding victim complicity. ${ }^{20}$ Even if passing victims avoid such complicity entirely, for example by widely distributing the material benefits of passing and by never standing idly by when visibly out group members are harmed in their presence, I contend that passing victims will still be engaged in a self-regarding variety of complicity. This second kind of complicity occurs when an individual participates in, passively allows, or benefits from a system that harms her. It is my contention that passing as privileged is an instance of self-regarding complicity, because the benefits of passing depend on the continued existence of a system that's still ultimately harmful to passing victims.

One way to conceptually distinguish victims and privileged individuals is that victims face wrongful constraints when they're recognized for who they are. This, after all, is why some victims choose to pass. And this is also why the strategy of passing always involves some cost or risk. Passing is facing a double bind that prevents victims from having what they want while also being themselves (or being with whom they want to be with, or being where they want to be), and opting for the former over the latter. And it often entails the insecurity of losing whatever they've gained, and possibly more, should their passing be

20. Indeed, one way to read Section 3 is as a sustained rejection of other-regarding complicity claims. 
discovered. It's not the same cost or risk in every case, and different victims will be affected in different ways and mind in different amounts, but the idea is that passing always involves a trade-off. This is something victims accept when they pass, or at least when they decide to keep passing. They're aware of the price they're paying, but consider it worth paying given their appraisal of the alternatives.

More specifically, the strategy employed by passing victims is to improve their lives or advance their interests by protecting or promoting some constituent of their well-being, but in a way that endangers or undermines a constituent of their well-being. Passing thus involves a well-being trade-off, and when it works, it works because that trade-off is net advantageous. Suppose the constituents of objective well-being are self-respect, progress in one's plans and projects, happiness, connection, autonomy, security, health, and valuable external goods. ${ }^{21}$ By passing, a victim might aim to advance her plans and projects, or to increase her autonomy, or to acquire valuable external goods, or to unlock preferred connections with privileged others, or so on. But the cost or risk of passing can be found on the same list: she might lose some self-respect, or strain her connection to family or fellow victims, or undermine her sense of security as she worries about the potential backlash of discovery. The trade-off can even involve the same constituent: a passing victim could gain self-respect by providing a better life for his children, but suffer a loss of self-respect because of the manner in which he's providing it.

The specific constituents being improved and impaired will vary from victim to victim and circumstance to circumstance, and there's no fixed answer about just how much passing victims will gain or lose. But victims can't pass without making some kind of well-being trade-off. And importantly, this trade-off isn't a mere opportunity cost, in the sense that everyone has to risk or give up something in order to do anything in life. It's a trade-off between two valuable constituents of well-being, and one that victims only consider making because oppression doesn't allow them, specifically, to protect and promote both constituents at the same time. To live the life they want under conditions of oppression, passing victims have to pay an ongoing cost or face an ongoing risk.

This last point helps explain why these well-being trade-offs are a form of self-regarding complicity. On my view, passing and resistance share an aim: they're both attempts to improve one's life or circumstances in the face of oppression. But whereas genuinely resisting agents attempt to improve their wellbeing by undermining, changing, or escaping the oppressive system that constrains their well-being, victims who pass decide they can't live without what

21. The details of the list are not crucial to the argument that follows. Particular constituents can be added or subtracted without affecting the structure of the trade-off. 
passing affords them, and can live without what passing costs them. They pass because the available trade-off aligns with their priorities and preferences. Be it human connection for self-respect or health for happiness, they judge that passing stands to improve their well-being overall. Yet even when they're absolutely correct in that judgment, their strategy for protecting and promoting their wellbeing depends on the continued existence of the very system that constrains their well-being in the first place.

Neither resisting victims nor passing victims are willing to accept being constrained. Both face well-being costs and risks because of that. But their strategy for improving their constrained well-being is different. Resisting victims try to eliminate or reduce those constraints. Passing victims keep those constraints in place, and instead focus on exploiting the manner in which they're distributed so as to avoid being constrained by them. By making ongoing well-being trade-offs that spare them from being identified and treated like victims by the constraining system, passing victims benefit from oppression existing in the form that it does. All while being harmed by that same system of oppression, because its constraints are the reason passing victims have to make do with those trade-offs. To pass as a well-being strategy is to be complicit in one's own oppression.

To be clear, making ongoing well-being trade-offs doesn't mean that passing victims will invariably experience less well-being than resisting victims. My argument doesn't depend on cost-benefit analysis, and I'm willing to concede that passing victims will sometimes fare better-especially since resistance can be a costly, long-term strategy, and can easily expose victims to retaliation. The temptation to pass exists for a reason, after all. But a strategy that depends on the continued existence of a system that's ultimately harmful to victims, and that does nothing to challenge the set of constraints that incentivize passing to begin with, is a structurally limited strategy for improving one's own well-being. At least when compared with attempts to remove or defeat the original constraints.

Just as my argument doesn't depend on cost-benefit analysis, to be clear, I also part ways with authors who contend that genuine resistance is necessary for victims to promote a particular constituent of well-being, or to flourish, or to be truly self-respecting under conditions of oppression. To pick one prominent example in the resistance literature, Carol Hay points to the ultimate moral value of our rational natures, and argues for an imperfect duty to engage in activities that protect our rational natures from the harms of oppression (2013: 122-146). ${ }^{22}$ She cites a variety of resistance strategies, including everything from direct political confrontation to the internal resistance of reminding oneself that oppressive norms and expectations are wrong (2012: 140ff.). But if I'm right that passing is a successful strategy under conditions of oppression, then it too can unlock

22. Hay doesn't discuss passing; her account contrasts resistance with non-resistance. 
these self-regarding benefits, so long as victims are careful with their trade-offs. We can easily imagine cases where passing as privileged either allows a victim to avoid the damage that oppression would do to her rational nature, or is at least compatible with resisting such harms internally (2012: 123ff.). However, this result shouldn't lead us to conclude that passing must not be a complicit measure, after all. Given the complexity of victims' circumstances, resistance and complicity aren't as mutually exclusive as the resistance literature tends to assume. Sometimes the same act has features of both resistance and complicity.

Another reason the complicity argument I've advanced departs from the work of theorists like Hay is because my criticism of passing doesn't attribute any decisive weight to goods like authenticity or self-respect or even one's rational nature, as depending on the victim and her circumstances, these goods can all be gained in the trade-off or lost in the trade-off. No particular constituent is central to my assessment of passing as a strategy, and no conception of the good life is assumed by it. What matters is the nature of the ongoing trade-offs on which the passing strategy generally depends.

Where does this leave us? I've argued that because passing victims are complicit in their own oppression, they have a structurally limited strategy for improving their own well-being. But that doesn't make passing impermissible. Why? First, because this consideration shouldn't be confused with a comprehensive verdict: cases of passing vary, and even when the trade-offs do work out in a victim's favor, other considerations may be strong enough to overwhelm this one, and affect the overall permissibility or impermissibility of passing. But second, self-regarding complicity doesn't automatically make passing impermissible because these victims aren't failing themselves. Even though they have a limited strategy for looking out for themselves, they are still looking out for themselves. Rather than accepting the level of constrained well-being normally afforded to victims in their situation, they're employing a strategy that allows them to make net marginal improvements to their well-being. Given that passing really can make a life go better, and given that victims aren't responsible for the choice situation in which they find themselves, I can see no support for the claim that this form of complicity is impermissible. Complicity isn't always wrong.

Some might deem this a weak conclusion. But I think this is how appropriately sensitive explorations of victim agency ought to go. Demonstrating that an action involves complicity doesn't end the conversation in one sweeping generalization or one decisive verdict. Double binds endure, and for victims, few options are without cost. The fact that a strategy, like passing as privileged, involves being complicit in one's own oppression is just a single consideration factoring into the question of how a person ought to respond to their oppression. We're still a long way off from understanding what it really means for victims 
to look out for themselves. And until we have that understanding, I think we should be hesitant about action-guidance that goes beyond evaluating the potential considerations shaping the choices of victims, and refrain from attempts to give an answer on their collective behalf. Anti-oppression theory should be slow and messy and cautious and particular-as complicated as the lives it attempts to model.

\section{Acknowledgments}

My thanks to Zehra Arat, Dorit Bar-On, Elizabeth Barnes, JC Beall, Sara Bernstein, Paul Bloomfield, Tilda Cvrkel, Helen Habermann Daly, Darci Doll, Tom Dougherty, John Exdell, Salvatore Florio, Miranda Fricker, Bruce Glymour, Sandy Goldberg, Jane Gordon, Amanda Greene, James Hamilton, Jason Hanna, Elizabeth Harman, Max Hayward, Jonathan Herington, Amelia Hicks, Suzy Killmister, Rebecca Kukla, Alycia LaGuardia-LoBianco, Amy Lara, Fred Lee, Hallie Liberto, Alice MacLachlan, Simon Căbulea May, Michaela McSweeney, Tom Meagher, Dana Miranda, Michael Morrell, Caryl Nuñez, Sara Protasi, Gabriel Rabin, Regina Rini, David Ripley, Debbie Roberts, Michael Robillard, Colena Sesanker, Lionel Shapiro, Nathan Sheff, Evelyn Simien, Paulina Sliwa, Matthew Smith, Natalie Stoljar, Fenner Tanswell, Rosa Terlazzo, Nick Treanor, Donald Wilson, my anonymous referees, and audiences at the American Philosophical Association, Amherst College, Kansas State University, the Midsummer Philosophy Workshop, Princeton University, and St Andrews. I've also benefited greatly from the intellectual environment at the University of Connecticut.

\section{References}

Bettcher, Talia Mae (2007). Evil Deceivers and Make-Believers: On Transphobic Violence and the Politics of Illusion. Hypatia, 22(3), 43-65. https://doi. org/10.1111/j.1527-2001.2007.tb01090.x

Brennan, Samantha (2011). Fashion and Sexual Identity, or Why Recognition Matters. In Jessica Wolfendale and Jeannette Kennett (Eds.), Fashion: Philosophy for Everyone (120-134). Wiley-Blackwell. https://doi.org/10.1002/9781444345568.ch8

Brennan, Samantha (2012a). Reply to Behrensen (part of: Margins Within the Marginal: Bi-invisibility and Intersexual Passing). In Dennis R. Cooley and Kelby Harrison (Eds.), Passing/Out: Sexual Identity Veiled and Revealed (196-198). Ashgate Publishing Limited.

Brennan, Samantha (2012b). "Those Shoes Are Definitely Bicurious": More Thoughts on the Politics of Fashion (part of: Margins Within the Marginal: Bi-invisibility and Intersexual Passing). In Dennis R. Cooley and Kelby Harrison (Eds.), Passing/Out: Sexual Identity Veiled and Revealed (171-180). Ashgate Publishing Limited. 
Card, Claudia (1999). Groping Through Moral Gray Zones. In Claudia Card (Ed.), On Feminist Ethics and Politics (3-26). University Press of Kansas.

Chekola, Mark (2012). The Moral Dimensions of Passing (part of: The Ontological Foundations of Passing). In Dennis R. Cooley and Kelby Harrison (Eds.), Passing/Out: Sexual Identity Veiled and Revealed (13-20). Ashgate Publishing Limited.

Cooley, Dennis R. (2012). Is There a Duty to Be Out? (part of: Complicating Reason(s) and Praxis for Coming Out). In Dennis R. Cooley and Kelby Harrison (Eds.), Passing/ Out: Sexual Identity Veiled and Revealed (43-50). Ashgate Publishing Limited.

Cooley, Dennis R. and Kelby Harrison (2012). Introduction. In Dennis R. Cooley and Kelby Harrison (Eds.), Passing/Out: Sexual Identity Veiled and Revealed (1-11). Ashgate Publishing Limited.

Cudd, Ann E. (1994). Oppression by Choice. Journal of Social Philosophy, 25(1), 22-44. https://doi.org/10.1111/j.1467-9833.1994.tb00347.x

Ginsberg, Elaine K. (1996). Introduction: The Politics of Passing. In Elaine K. Ginsberg (Ed.), Passing and the Fictions of Identity (1-18). Duke University Press. https://doi. org/10.1215/9780822382027-001

Goffman, Erving (1963). Stigma: Notes on the Management of Spoiled Identity. Simon \& Schuster.

Halwani, Raja (2002). Outing and Virtue Ethics. Journal of Applied Philosophy, 19(2), 141154. https://doi.org/10.1111/1468-5930.00211

Harrison, Kelby (2012). Power Over the Passing Subject: Creating Ethics Under Oppression (part of: Power, Oppression, and Passing). In Dennis R. Cooley and Kelby Harrison (Eds.), Passing/Out: Sexual Identity Veiled and Revealed (83-92). Ashgate Publishing Limited.

Harrison, Kelby (2013). Sexual Deceit: The Ethics of Passing. Lexington Books.

Hay, Carol (2013). Kantianism, Liberalism, and Feminism: Resisting Oppression. Palgrave Macmillan. https://doi.org/10.1057/9781137003904

Hobbs, Allyson (2014). A Chosen Exile: A History of Racial Passing in American Life. Harvard University Press. https://doi.org/10.4159/harvard.9780674735811

MacLachlan, Alice (2012). Closet Doors and Stage Lights: On the Goods of Out. Social Theory and Practice, 38(2), 302-332. https://doi.org/10.5840/soctheorpract201238217

MacLachlan, Alice and Susanne Sreedhar (2012). Complicating "Out": The Case of Queer Femmes (part of: Complicating Reason(s) and Praxis for Coming Out). In Dennis R. Cooley and Kelby Harrison (Eds.), Passing/Out: Sexual Identity Veiled and Revealed (51-60). Ashgate Publishing Limited.

Mills, Claudia (1999). "Passing": The Ethics of Pretending to Be What You Are Not. Social Theory and Practice, 25(1), 29-51. https://doi.org/10.5840/soctheorpract19992511

Mohr, Richard D. (1992). Gay Ideas: Outing and Other Controversies. Beacon Press.

NCVAP (2013). Hate Violence against Transgender Communities Factsheet. Retrieved from http://www.avp.org/storage/documents/ncavp_transhvfactsheet.pdf

Oshana, Marina (2010). The Importance of How We See Ourselves: Self-Identity and Responsible Agency. Lexington Books.

Piper, Adrian (1996). Passing for White, Passing for Black. In Elaine K. Ginsberg (Ed.), Passing and the Fictions of Identity (234-269). Duke University Press. https://doi. org/10.1215/9780822382027-011

Samuels, Ellen (2003). My Body, My Closet: Invisible Disability and the Limits of ComingOut Discourse. GLQ: A Journal of Lesbian and Gay Studies, 9(1-2), 233-255. https://doi. org/10.1215/10642684-9-1-2-233 
Snorton, C. Riley (2009). "A New Hope": The Psychic Life of Passing. Hypatia, 24(3), 7792. https://doi.org/10.1111/j.1527-2001.2009.01046.x

Stoljar, Natalie (ms). Two Conceptions of 'One's Own': Distinguishing between Authenticity and Autonomy. Manuscript in preparation.

Stone, Sandy (1992). The Empire Strikes Back: A Posttransexual Manifesto. Camera Obscura, 10(2 29), 150-176. https://doi.org/10.1215/02705346-10-2_29-150

Yoshino, Kenji (2007). Covering: The Hidden Assault on Our Civil Rights. Random House. 